\title{
Where have all the hip fractures gone?
}

\section{K. C. Wong ${ }^{1}$ (D) - J. W. G. Cheok $^{1}$ - K. X. K. Tay ${ }^{1}$ - S. B. Koh ${ }^{1}$ • T. S. Howe ${ }^{1}$}

Received: 6 May 2020 / Accepted: 25 May 2020 / Published online: 3 June 2020

(C) International Osteoporosis Foundation and National Osteoporosis Foundation 2020

\section{Dear Editor,}

Amidst the coronavirus disease 2019 (COVID-19) pandemic, we have noticed a marked unexplained decrease in osteoporotic hip fracture surgeries in our institution. This is baffling and mirrors the unexplained reported decrease in heart attacks and strokes [1]. We also looked at time to surgery to see if our protocols during COVID-19 had compromised fracture care.

Singapore's Disease Outbreak Response System Condition (DORSCON) status escalated to Orange [2] in response to worsening community spread. Resource and manpower considerations affected all departments in our institution including the Department of Orthopedic Surgery [3]. This prompted an investigation into the quality of care afforded to hip fracture patients during the COVID-19 pandemic. We hypothesized that a well-executed treatment protocol ensures that care afforded to hip fracture patients should remain unaffected.

We compared surgically managed hip fracture patients admitted 2 months before escalation to DORSCON Orange ("pre-COVID"), with patients admitted 2 months after ("post-COVID"). Indications for hip fracture surgery remain unchanged. We collected demographic data, time taken to be admitted to ward from the Emergency Department, as well as time elapsed between ward admission and surgery.

We found a sharp decrease in hip fractures during the COVID-19 pandemic, with 76 pre-COVID patients compared with 35 post-COVID patients ( $54 \%$ decrease). There were no differences in demographic data, time to admission $(2.0 \pm 1.2$ versus $1.7 \pm 0.9$; mean difference, $0.3 ; 95 \% \mathrm{CI},-0.2$ to 0.7 ; $p=0.20)$, and time to surgery $(60.7 \pm 45.1$ versus $45.0 \pm 42.3$; mean difference, 15.7 ; $95 \% \mathrm{CI},-2.2$ to $33.6 ; p=0.084$ ) between both cohorts (Table 1).

Our study population is a bellwether of orthopedic trauma care as most osteoporotic hip fractures are now treated

K. C. Wong

khaicheong.wong@mohh.com.sg

1 Department of Orthopedic Surgery, Singapore General Hospital Academia, Level 420 College Road, Singapore 169856, Singapore surgically due to benefits of reduced length of hospital stay and improved rehabilitation [4]. In Singapore, emergency services have defined evacuation protocols to identified public hospitals. As the vast majority of hip fractures usually require emergency services for delivery to hospitals, which has not changed from the pre-COVID era, the proportion of hip fracture patients brought to our institution should not have changed. A similar pattern was noticed in myocardial infarctions in the USA where up to a $60 \%$ reduction in admissions was reported, postulated to be due to COVID-19 instilling a fear of face-to-face medical care as people would rather stay at home than risk seeking treatment [1].

With the need for additional perioperative precautions during this pandemic [5], detrimental effects on the ability of an overwhelmed healthcare system to provide timely hip fracture care is understandable, evident in increased delay in time to surgery [6]. However, despite the implementation of department segregation protocols which disrupt routine workflow, there was no delay in time to admission and surgery in our study population. This suggests that an established bundled care protocol for hip fractures can withstand the challenges during a pandemic and ensure that the standard of care is not compromised.

Will we eventually see patients with late sequelae of untreated fractures? Is treatment being compromised, leading to poorer functional performance and quality of life? Further

Table 1 Demographic data and treatment protocol parameters

\begin{tabular}{llll}
\hline & $\begin{array}{l}\text { Pre- } \\
\text { COVID } \\
(n=76)\end{array}$ & $\begin{array}{l}\text { Post- } \\
\text { COVID } \\
(n=35)\end{array}$ & $p$ value \\
\hline Gender (female:male) & $44: 32$ & $22: 13$ & $p=0.621$ \\
Age (years) & $79.6 \pm 8.5$ & $76.3 \pm 8.4$ & $p=0.059$ \\
ASA class $(n)$ & & & $p=0.483$ \\
II & 31 & 18 & \\
III & 44 & 17 & \\
IV & 1 & 0 & $p=0.200$ \\
Time to ward (hours) & $2.0 \pm 1.2$ & $1.7 \pm 0.9$ & $p=0.084$ \\
Time to surgery (hours) & $60.7 \pm 45.1$ & $45.0 \pm 42.3$ & \\
\hline
\end{tabular}


studies will be essential in evaluating the downstream effects on patients with hip fractures. The question of whether there will be a rebound in osteoporotic hip fractures after the current COVID crisis is over remains unanswered, but we should plan for this eventuality.

\section{Compliance with ethical standards}

\section{Conflicts of interest None.}

Ethics approval Institutional review board approval was obtained without the need for consent as de-identified data was used.

Human and animal rights This article does not contain any studies with human participants or animals performed by any of the authors.

\section{References}

1. Krumholz H (2020) Where have all the heart attacks gone?. The New York Times
2. What do the different DORSCON levels mean. Gov.sg. https://www. gov.sg/article/what-do-the-different-dorscon-levels-mean. Published 2020

3. Liow M, Tay K, Yeo N et al (2020) Ensuring business continuity of musculoskeletal care during the COVID-19 pandemic: experience of a tertiary Orthopaedic Surgery Department in Singapore. J Bone Joint Surg 5:e0050. https://doi.org/10.2106/JBJS.OA.20.00050

4. Handoll HH, Parker MJ (2008) Conservative versus operative treatment for hip fractures in adults. Cochrane Database Syst Rev (3): CD000337. Published 2008 Jul 16. https://doi.org/10.1002/ 14651858.CD000337.pub2

5. Awad ME, Rumley JCL, Vazquez JA, Devine JG (2020) Perioperative considerations in urgent surgical care of suspected and confirmed COVID-19 orthopedic patients: operating rooms protocols and recommendations in the current COVID-19 pandemic [published online ahead of print, 2020 Apr 10]. J Am Acad Orthop Surg. https://doi.org/10.5435/JAAOS-D-20-00227

6. Williams J, Kumar A (2020) The effect of the COVID-19 pandemic on hip fracture care. The Transient Journal of Trauma, Orthopaedics and the Coronavirus

Publisher's note Springer Nature remains neutral with regard to jurisdictional claims in published maps and institutional affiliations. 